\title{
Electronic hydraulic lithotripsy by antegrade digital cholangioscopy through endoscopic ultrasound-guided hepaticojejunostomy
}

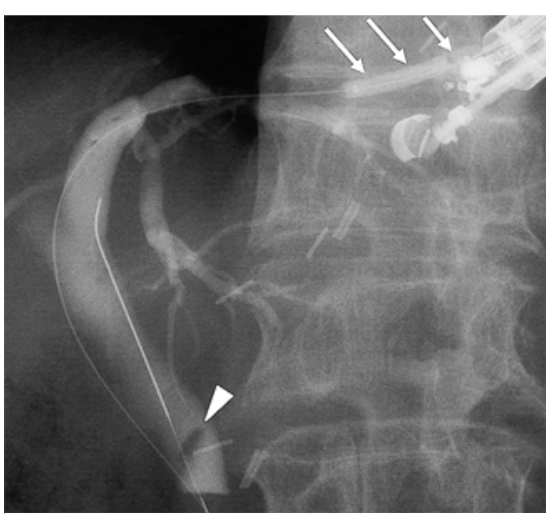

- Fig. 1 Fluoroscopic image showing a common bile duct stone (arrowhead) and balloon dilator (arrows).

This report describes antegrade electronic hydraulic lithotripsy (Lithotron EL 27; Walz Elektronik, Rohrdorf, Germany) using a digital peroral cholangioscope (SpyGlass DS System; Boston Scientific, Marlborough, Massachusetts, USA) $[1,2]$ through an endoscopic ultrasound (EUS)-guided hepaticojejunostomy route for common bile duct (CBD) stones ( Video 1 ).

A 77-year-old man, who underwent total gastrectomy with a Roux-en-Y procedure for gastric cancer, presented with cholangitis caused by CBD stones. Endoscopic transpapillary drainage was attempted, but the scope could not be inserted into the ampulla; therefore, EUS-guided hepaticojejunostomy was performed.

From the Roux-en-Y jejunum, the dilated intrahepatic bile duct was punctured with a 19-gauge needle under EUS. After guidewire insertion toward the distal bile duct, the puncture site was dilated using a balloon dilator (diameter $4 \mathrm{~mm}$, REN; Kaneka Medix, Osaka, Japan) (\$ Fig.1). A covered metal stent (diameter $8 \mathrm{~mm}$, length $8 \mathrm{~cm}$, Niti-S; Taewoong Medical, Gyeonggi-do, South Korea) was inserted between the intrahepatic bile duct and the Roux-en-Y jejunum ( $\mathbf{F i g . 2}$ ). The following day, the patient's cholangitis was

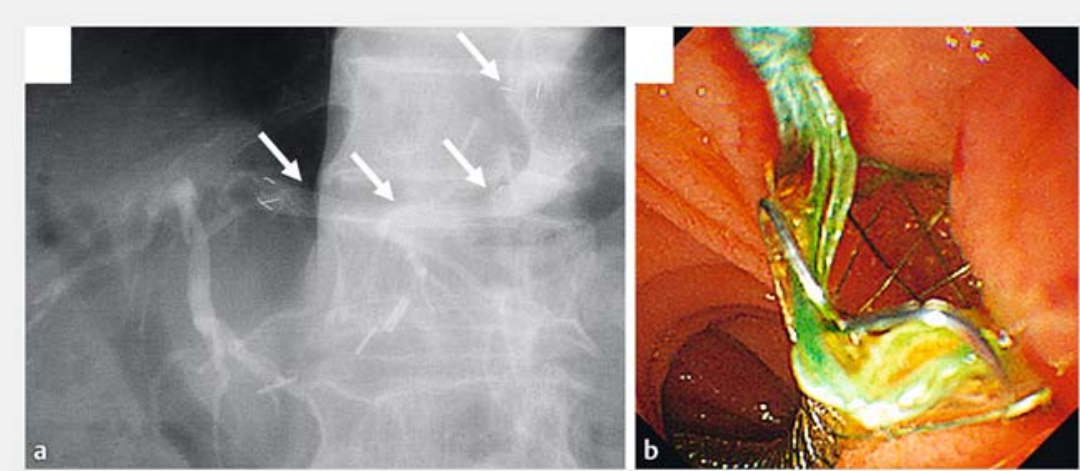

- Fig. 2 Stent deployment between the intrahepatic bile duct and the Roux-en-Y jejunum (arrows). a Fluoroscopic image. b Endoscopic image.

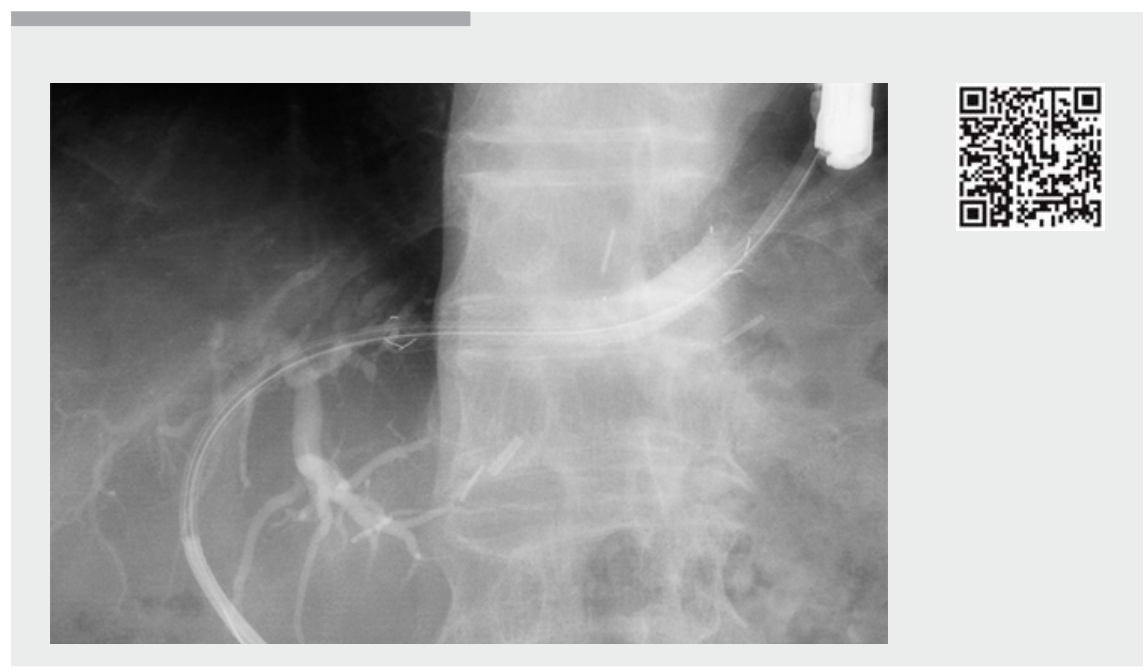

Video 1 Antegrade electronic hydraulic lithotripsy using a digital peroral cholangioscope through an endoscopic ultrasound-guided hepaticojejunostomy fistula. This novel method could become a rescue procedure when the conventional transpapillary approach is unsuccessful.

markedly improved, and he was discharged 3 days after surgery.

The patient was re-admitted to our hospital 4 weeks later to continue treatment for CBD stones. The cholangioscope was inserted over the guidewire through the metal stent ( $\triangleright$ Fig. $\mathbf{3}$ ), and the CBD stones were revealed by cholangioscopy ( $>$ Fig. $4 \mathrm{a})$. The stones were crushed by elec- tronic hydraulic lithotripsy ( $\triangleright$ Fig.4b). Subsequently, the metal stent was removed and a balloon dilator was inserted into the fistula toward the ampulla and dilated up to $12 \mathrm{~mm}$ ( $\triangleright$ Fig. 5 a). The CBD stones were pushed out into the digestive tract in an antegrade fashion using a balloon catheter ( $\mathbf{F i g} \mathbf{5} \mathbf{b}$ ). Finally, a singlepigtail plastic stent $(7 \mathrm{Fr}, 20 \mathrm{~cm}$ length) 


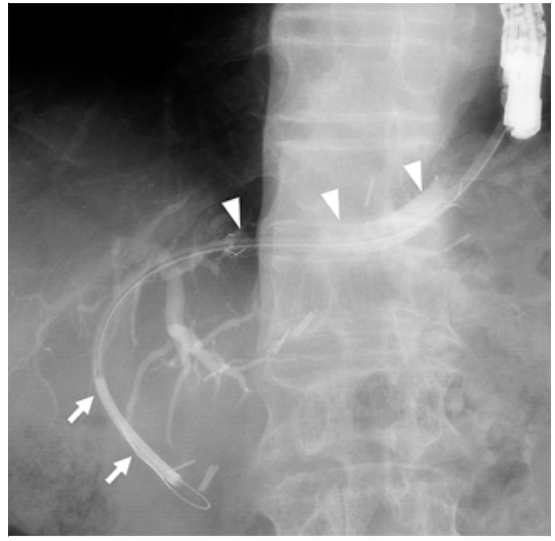

Fig. 3 Insertion of the digital peroral cholangioscope (arrows) over the guidewire through the metal stent (arrowheads).
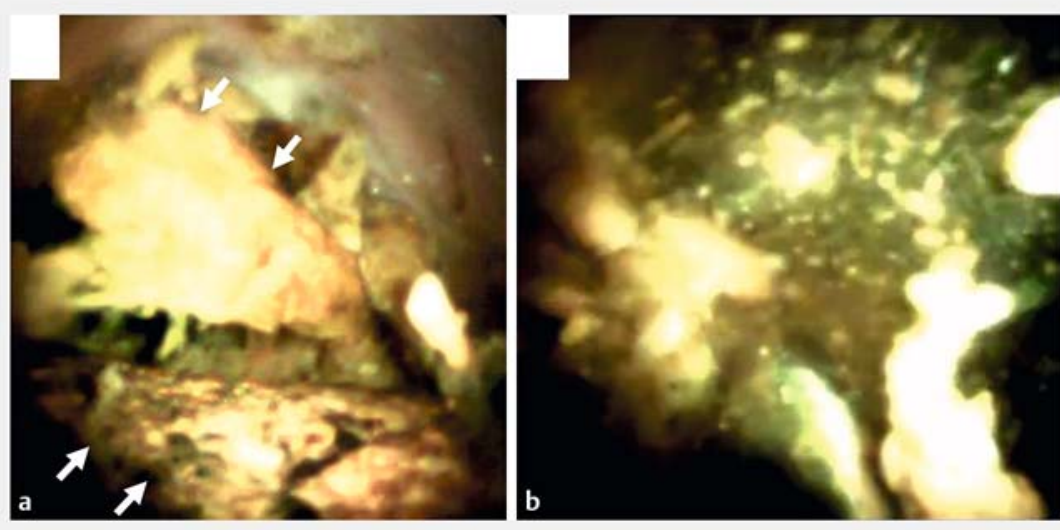

- Fig. 4 Treatment of common bile duct (CBD) stones. a Cholangioscopic view showing CBD stones (arrows). b Crushing of CBD stones by electronic hydraulic lithotripsy.
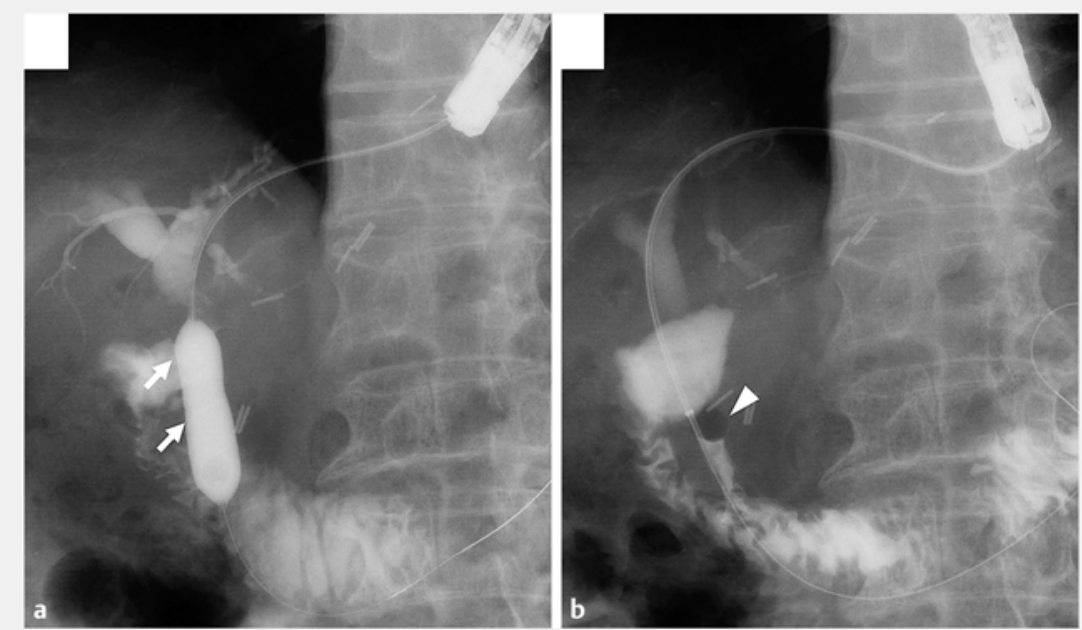

- Fig. 5 Removal of common bile duct (CBD) stones. a Fluoroscopic image showing endoscopic papillary balloon dilation (arrows). b Use of a balloon catheter (arrowhead) to push $\mathrm{CBD}$ stones into the digestive tract in an antegrade manner.

[3] was deployed between the CBD and the Roux-en-Y jejunum ( $\triangleright$ Fig. 6 ). The patient resumed eating 4 days after surgery with no adverse effects, and was discharged 7 days after surgery.

Endoscopy_UCTN_Code_TTT_1AR_2AH

Competing interests
The Authors

Yasuo Otsuka, Ken Kamata, Mamoru

Takenaka, Kosuke Minaga, Hidekazu Tanaka, Masatoshi Kudo

Department of Gastroenterology and Hepatology, Kindai University School of Medicine, Osaka-Sayama, Japan

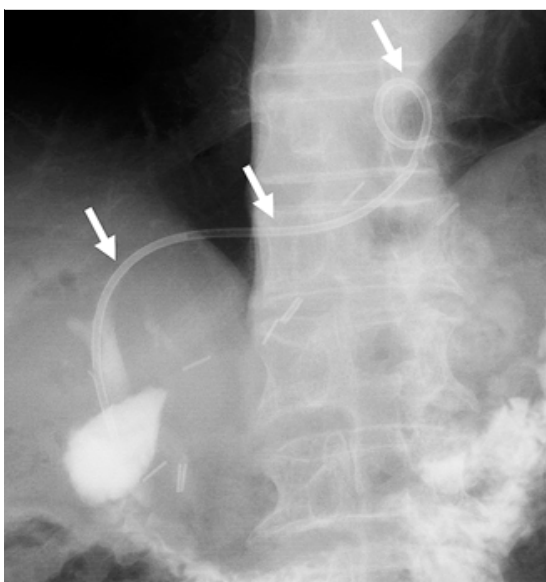

- Fig. 6 Fluoroscopic image showing deployment of a single-pigtail plastic stent between the common bile duct and the Roux-en-Y jejunum (arrows).

Corresponding author

Ken Kamata, MD, PhD

Department of Gastroenterology and Hepatology, Kindai University Faculty of Medicine, 377-2 Ohno-Higashi, OsakaSayama, 589-8511, Japan

Fax: $+81-72-3672880$

ky11@leto.eonet.ne.jp 


\section{References}

[1] Navaneethan U, Hasan MK, Kommaraju K et al. Digital, single-operator cholangiopancreatoscopy in the diagnosis and management of pancreatobiliary disorders: a multicenter clinical experience (with video). Gastrointest Endosc 2016; 84: 649-655

[2] Tanaka R, Itoi T, Honjo M et al. New digital cholangiopancreatoscopy for diagnosis and therapy of pancreaticobiliary diseases (with videos). J Hepatobiliary Pancreat Sci 2016; 23: $220-226$
[3] Umeda ], Itoi T, Tsuchiya T et al. A newly designed plastic stent for EUS-guided hepaticogastrostomy: a prospective preliminary feasibility study (with videos). Gastrointest Endosc 2015; 82: 390 - 396

\section{Bibliography}

DOI https://doi.org/10.1055/s-0043-119971

Published online: 9.10.2017

Endoscopy 2017; 49: E316-E318

(c) Georg Thieme Verlag KC

Stuttgart · New York

ISSN 0013-726X

\section{ENDOSCOPY E-VIDEOS}

https://eref.thieme.de/e-videos

回局 Endoscopy E-Videos is a free access online section, reporting 回: on interesting cases and new techniques in gastroenterological endoscopy. All papers include a high quality video and all contributions are freely accessible online.

This section has its own submission website at

https://mc.manuscriptcentral.com/e-videos 